\title{
Pengaruh Variasi Tekanan Kompaksi Powder Metallurgy Elektroda Metal Matrix Composites Tembaga-Grafit terhadap Material Removal Rate dan Electrode Relative Wear pada Proses EDM Mesin Chimer EZ
}

\author{
Dwi Handoko ${ }^{1)}$, Sutrisno ${ }^{2)}$, Agus Rohermanto ${ }^{3)}$. \\ ${ }^{1,2,3)}$ Jurusan Teknik Mesin Politeknik Negeri Pontianak \\ E-mail: ${ }^{1)}$ handwi66@yahoo.co.id
}

\begin{abstract}
Abstrak
Pada penelitian ini dilakukan pembuatan metal matrix composite dari bahan serbuk tembaga murni yang akan dipadu dengan bahan penguat berupa serbuk grafit yang dilanjutkan dengan pengujian pada mesin EDM. Metode pencampuran kedua material ini dilakukan dengan proses powder metalurgi melalui tahapan pencampuran (mixing), penekanan (compaction) dan dilanjutkan dengan proses pemanasan dengan suhu $800{ }^{\circ} \mathrm{C}$ (sintering). Pada penelitian ini ingin diketahui pengaruh tekanan akibat proses powder metalurgi terhadap laju keausan material (MRR) dan laju keausan elektroda (ERR) pada material baja ST.37 mesin EDM Chimer EZ dengan parameter pemakan tetap, arus 2 Ampere dan kedalaman 5 mm. Pengujian yang dilakukan yaitu kekerasan dan struktur mikro. Dari hasil penelitian ini menunjukkan dengan semakin meningkatnya tekanan kompaksi laju keausan material MRR dan kekerasan semakin meningkat, sementara laju keausan terendah terjadi pada tekanan kompaksi $25.000 \mathrm{KN}$.
\end{abstract}

Kata Kunci: MMC, EDM, MRR, ERR, Elektrode.

\section{Abstract}

In this study, a metal matrix composite was made from pure copper powder which would be combined with a reinforcing material in the form of graphite powder followed by testing on an EDM machine. The method of mixing the two materials is carried out by a powder metallurgy process through the stages of mixing, pressing (compaction) and followed by a heating process with a temperature of $800{ }^{\circ} \mathrm{C}$ (sintering). In this study, we want to know the effect of pressure due to the powder metallurgy process on the material wear rate (MRR) and the electrode wear rate (ERR) on the steel material of ST.37 Chimer EZ EDM machine with fixed feeder parameters, a current of 2 Ampere and a depth of $5 \mathrm{~mm}$. The tests carried out were hardness and micro structure. The results of this study indicate that with the increasing of the compacting pressure, the wear rate of MRR material and the hardness increases, while the lowest wear rate occurs at a compacting pressure of $25,000 \mathrm{KN}$.

Keywords: MMC, EDM, MRR, ERR, Electrode. 


\section{PENDAHULUAN}

Electrical Discharge Machine (EDM) adalah merupakan proses pemesinan non konvensional, dimana pahat yang digunakan berupa elektroda yang akan mengikis benda kerja sesuai dengan bentuk pahatnya. Mesin mengendalikan pergerakan pahat untuk mengikis benda kerja dan menimbulkan percikan bunga api listrik yang berfrekwensi tinggi (spark). Dalam proses EDM tidak terjadi proses kontak dan gaya pemotongan antara pahat dan material benda kerja (adanya jarak/ celah) Hal ini mengakibatkan tidak adanya tegangan, chatter, dan masalah getaran seperti yang pasti terjadi pada proses pemesinan konvensional.

Keuntungan dari penggunaan mesin EDM adalah dapat digunakan untuk pemesinan pada logam-logam yang tidak mungkin dapat proses dengan menggunakan metode pemesinan konvensional, selain itu EDM juga dapat digunakan untuk memotong sudut kecil atau sudut dengan bentuk tak beraturan seperti pada logam titanium, inconel carbide dan lain lain.

Disisi lain EDM juga memiliki kelemahan seperti, hanya dapat digunakan untuk benda-benda yang dapat dialiri listrik atau benda-benda yang bersifat konduktif, selain itu elektroda yang digunakan lambat laun juga akan mengalami keausan dimana pada saat terjadinya proses pengikisan material benda kerja (Material Remove Ratel MRR), sebagian permukaan elektroda juga akan terkikis oleh panas akibat dari loncatan bunga api hal itu bisa saja disebabkan oleh besarnya arus listrik dan tingginya frekuensi bunga api (Electroda Remove Rate/ ERR).

Penggabungan antara material logam dengan logam atau non logam menjadi sebuah komposit matriks logam (MMCs, Metal Matrix Composites) telah yang banyak dilakukan. Pembuatan komposit matriks logam (MMCs) dengan material penguat partikel, dapat dilakukan dengan proses Powder Metallurgy yaitu dengan tahapan: pencampuran serbuk (mixing), kompaksi serbuk (compaction), dan proses sinter. Kelebihan metode metalurgi serbuk diantaranya adalah dapat diperoleh bentuk akhir komponen sehingga mengurangi biaya permesinan, mengurangi tahap-tahap proses produksi selanjutnya, laju produksi yang tinggi sehingga sangat cocok untuk produksi massal dan hampir tanpa material limbah, selain itu dengan proses ini dapat dibuat material yang memiliki toleransi ketat dan bentuk bervariasi atau sulit dilakukan dengan pemesinan konvensional [1][2][3].

Adapun yang menjadi fokus pada penelitian ini adalah: mengetahui pengaruh variasi tekanan kompaksi powder metallurgy terhadap material removal rate dan electrode relative wear elektroda metal matrix composites tembaga dengan penguat grafit pada proses EDM".

Berbagai penelitian yang telah dipublikasikan berkaitan dengan penelitian ini adalah sebagai berikut: Ahmad Junaidi melakukan penelitian terhadap pengaruh variasi temperatur sinter paduan tembaga dan karbon hasil proses metalurgi serbuk, hasil optimum pada tekanan kompaksi $400 \mathrm{MPa}$ dan suhu sintering $900{ }^{\circ} \mathrm{C}$ [4].

Pengaruh Variasi Tekanan Kompaksi Powder Metallurgy Elektroda Metal Matrix Composites Tembaga-Grafit terhadap Material Removal Rate dan Electrode Relative Wear pada Proses EDM Mesin Chimer EZ

(Dwi Handoko, Sutrisno, Agus Rohermanto) 
Hubungan jenis elektroda dan grafit proses EDM pada baja karbon rendah, hasil yang didapat yaitu dengan menggunakan elektroda grafit didapat harga MRR yang lebih baik dari pada tembaga [5][6].

Ahmad Junaidi melakukan penelitian pengaruh temperatur sinter terhadap kekerasan elektroda tembaga-5\% karbon yang dibuat dengan metode serbuk metalurgi, Percobaan dilakukan terhadap berbagai variasi kompaksi dan variasi suhu sinter dengan komposisi $95 \% \mathrm{Cu}$ dan 5\% C. Tiap benda uji dilakukan percobaan kekerasan. Hasil percobaan menunjukkan bahwa secara umum terdapat kecendrungan dengan meningkatnya beban kompaksi, kekerasan akan meningkat, makin tinggi suhu sinter makin baik konsolidasi serbuk [7].

Pengukuran Material Removal Rate (MRR) dan Electrode Relative Wear (ERW). Material Removal Rate adalah laju pengerjaan atau pemakanan material terhadap waktu dengan menggunakan elektroda EDM. MRR diukur dengan membagi berat benda kerja sebelum dan setelah proses machining terhadap waktu yang dicapai atau volume material yang telah dikerjakan terhadap waktu [8]. Persamaan yang digunakan untuk menentukan nilai Material Removal Rate :

Dimana :

$$
M R R=\frac{W_{b}-W_{a}}{t_{m}}(\mathrm{gr} / \mathrm{min})
$$

$\mathrm{Wb}$ : berat benda kerja sebelum machining (gr)

Wa : berat benda kerja setelah machining (gr)

tm : waktu yang digunakan untuk proses machining (min)

Electrode Relative Wear adalah laju keausan/material removal yang tejadi pada elektroda (pahat), nilai Electrode Relative Wear dapat dihitung dengan menggunakan persamaan :

$$
E R W=\frac{E W W}{W R W} \times 100 \%
$$

Dimana :

EWW : selisih berat elektroda sebelum dan setelah digunakan (gr)

WRW: selisih berat benda kerja sebelum dan setelah dikerjakan (gr)

\section{METODE PENELITIAN}

Metode penelitian dalam penelitian ini adalah menggunakan metode eksperimen. Metode eksperimen merupakan salah satu metode penelitian yang mengadakan kegiatan percobaan untuk melihat suatu hasil dan hasil ini akan menegaskan kedudukan hubungan (sebab-akibat) antara variabel yang diteliti.

Langkah-langkah yang dilakukan yaitu pembuatan elektroda EDM dengan proses Powder metalurgi, dari bahan tembaga dan grafit meliputi pencampuran, kompaksi dan sintering pada temperature $800{ }^{\circ} \mathrm{C}$, Pembuatan benda kerja dari bahan St. 37 dengan diameter $25 \mathrm{~mm}$ dan pembuatan alat cetak (Dies) dengan diameter $12 \mathrm{~mm}$ dan panjang $150 \mathrm{~mm}$. Selanjutnya melakukan pencetakan bahan elektroda dengan variasi tekanan $20.000 \mathrm{KN}, 25.000 \mathrm{KN}, 30.000 \mathrm{KN}$ dan 35.000 KN dengan menggunakan Universal Testing Machine setelah itu dilakukan penimbangan berat awal elektroda dan benda kerja sebelum proses EDM. 
Setelah Elektroda dibuat dilanjutkan dengan melakukan proses EDM dengan masing-masing elektroda kemudian dilakukan penimbangan berat akhir elektroda dan benda kerja setelah proses EDM. Akhirnya dilakukan dilakukan pengujian kekerasan dengan menggunakan mesin uji Rockwell yang ada di laboratorium Teknik Mesin Polnep dan dilakukan analisa struktur mikro dengan mikroskop mikrostruktur.

Adapun langkah-langkah metodologi yang dilakukan pada penelitian ini dapat secara keseluruhan dapat dilihat pada flow chart dibawah ini :

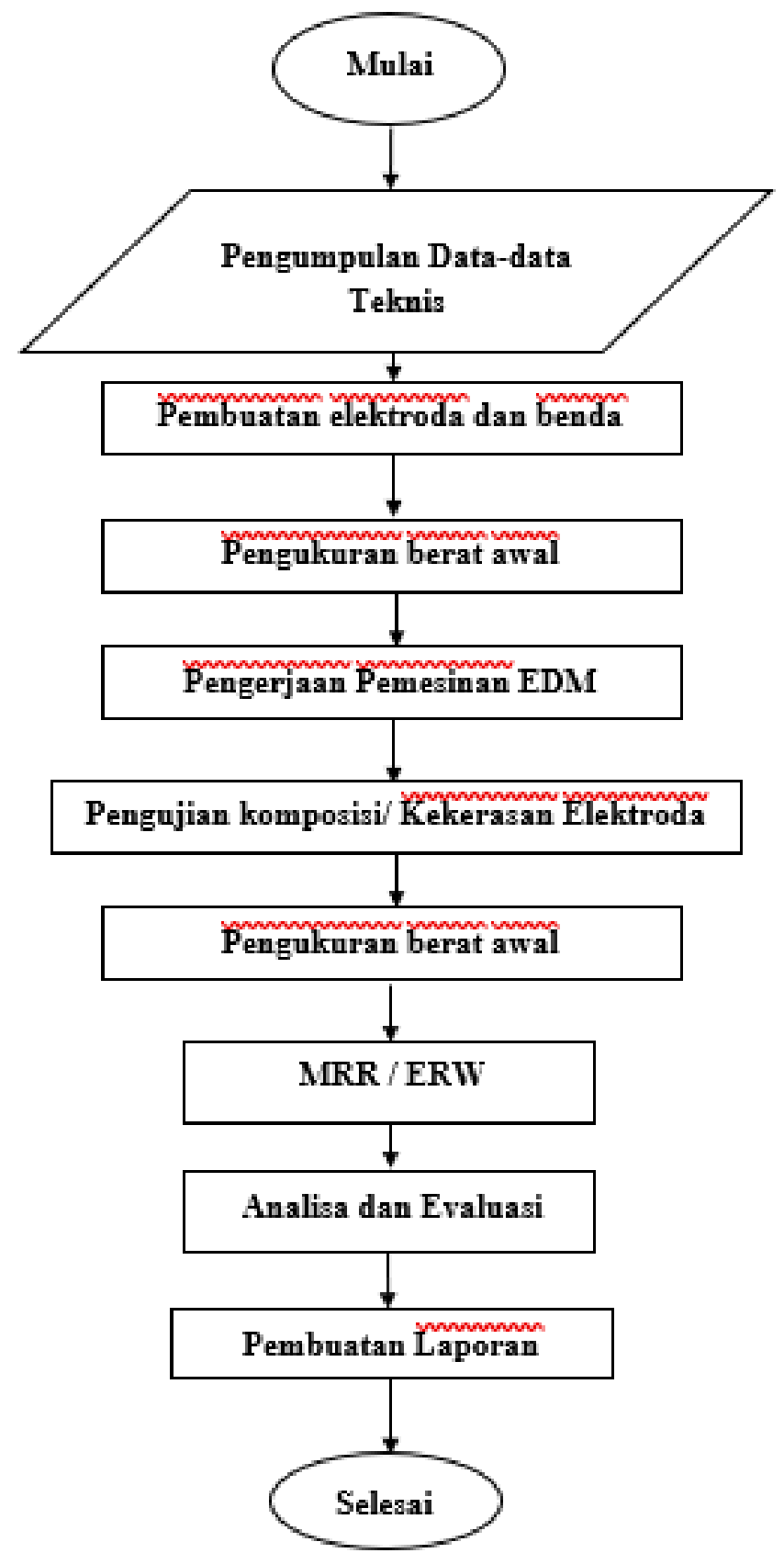

Gambar 1. Flow chart penelitian

Pengaruh Variasi Tekanan Kompaksi Powder Metallurgy Elektroda Metal Matrix Composites Tembaga-Grafit terhadap Material Removal Rate dan Electrode Relative Wear pada Proses EDM Mesin Chimer EZ

(Dwi Handoko, Sutrisno, Agus Rohermanto) 


\section{HASIL DAN PEMBAHASAN}

Berikut ini data MRR, ERW dan kekerasan material elektroda setelah dilakukan pemesinan EDM pada masing masing elektroda dengan arus pemakanan sebesar 2 Ampere :

Tabel 1 : Data Hasil MRR

\begin{tabular}{|c|c|c|c|}
\hline \multirow{2}{*}{$\begin{array}{l}\text { Benda } \\
\text { uji }\end{array}$} & \multirow[b]{2}{*}{ Tekanan } & MRR & \multirow[b]{2}{*}{ Standev } \\
\hline & & $\begin{array}{l}\text { (gram/ } \\
\text { min) }\end{array}$ & \\
\hline 1 & \multirow{4}{*}{$\begin{array}{l}20.000 \\
\mathrm{~N}\end{array}$} & 0.03466 & \multirow{4}{*}{0.00107} \\
\hline 2 & & 0.03565 & \\
\hline 3 & & 0.03649 & \\
\hline \multirow[t]{2}{*}{4} & & 0.03407 & \\
\hline & $\begin{array}{l}\text { Rata- } \\
\text { rata }\end{array}$ & 0.03522 & \\
\hline 1 & \multirow{4}{*}{$\begin{array}{l}25.000 \\
\mathrm{~N}\end{array}$} & 0.03709 & \multirow{4}{*}{0.00388} \\
\hline 2 & & 0.03685 & \\
\hline 3 & & 0.03731 & \\
\hline \multirow[t]{2}{*}{4} & & 0.04483 & \\
\hline & $\begin{array}{l}\text { Rata- } \\
\text { rata }\end{array}$ & 0.03902 & \\
\hline 1 & \multirow{4}{*}{$\begin{array}{l}30.000 \\
\mathrm{~N}\end{array}$} & 0.04188 & \multirow{4}{*}{0.00660} \\
\hline 2 & & 0.03610 & \\
\hline 3 & & 0.03400 & \\
\hline \multirow[t]{2}{*}{4} & & 0.04017 & \\
\hline & $\begin{array}{l}\text { Rata- } \\
\text { rata }\end{array}$ & 0.03804 & \\
\hline 1 & \multirow{4}{*}{$\begin{array}{l}35.000 \\
\mathrm{~N}\end{array}$} & 0.03324 & \multirow{4}{*}{0.00471} \\
\hline 2 & & 0.03386 & \\
\hline 3 & & 0.04095 & \\
\hline 4 & & 0.04233 & \\
\hline & $\begin{array}{l}\text { Rata- } \\
\text { rata }\end{array}$ & 0.03760 & \\
\hline
\end{tabular}

Tabel 2 : Data Hasil ERW

\begin{tabular}{|c|c|c|c|}
\hline \multirow{2}{*}{$\begin{array}{r}\text { Benda } \\
\text { uji }\end{array}$} & \multirow[b]{2}{*}{ Tekanan } & ERW & \multirow[b]{2}{*}{ Standev } \\
\hline & & $(\%)$ & \\
\hline 1 & \multirow{4}{*}{$20.000 \mathrm{~N}$} & 3.39 & \multirow{4}{*}{0.65} \\
\hline 2 & & 4.29 & \\
\hline 3 & & 3.78 & \\
\hline \multirow[t]{2}{*}{4} & & 2.76 & \\
\hline & Rata-rata & 3.56 & \\
\hline 1 & \multirow{4}{*}{$25.000 \mathrm{~N}$} & 3.30 & \multirow{4}{*}{0.11} \\
\hline 2 & & 3.45 & \\
\hline 3 & & 3.29 & \\
\hline \multirow[t]{2}{*}{4} & & 3.51 & \\
\hline & Rata-rata & 3.39 & \\
\hline 1 & \multirow{4}{*}{$30.000 \mathrm{~N}$} & 4.35 & \multirow{4}{*}{0.43182} \\
\hline 2 & & 3.75 & \\
\hline 3 & & 3.57 & \\
\hline \multirow[t]{2}{*}{4} & & 3.34 & \\
\hline & Rata-rata & 3.75 & \\
\hline 1 & \multirow{4}{*}{$35.000 \mathrm{~N}$} & 4.13 & \multirow{4}{*}{0.28} \\
\hline 2 & & 4.39 & \\
\hline 3 & & 4.79 & \\
\hline \multirow[t]{2}{*}{4} & & 4.31 & \\
\hline & Rata-rata & 4.41 & \\
\hline
\end{tabular}


Tabel 3 Hasil Uji Kekerasan Material Elektroda

\begin{tabular}{|c|c|c|}
\hline Tekanan & HRB & Standev \\
\hline \multirow{4}{*}{$20.000 \mathrm{~N}$} & 27 & \multirow{4}{*}{2.160247} \\
\hline & 28 & \\
\hline & 23 & \\
\hline & 26 & \\
\hline Rata-rata & 26 & \\
\hline \multirow{4}{*}{$25.000 \mathrm{~N}$} & 50 & \multirow{4}{*}{1.443376} \\
\hline & 48 & \\
\hline & 48 & \\
\hline & 46 & \\
\hline Rata-rata & 48 & \\
\hline \multirow{4}{*}{$30.000 \mathrm{~N}$} & 68 & \multirow{4}{*}{2.322893} \\
\hline & 70 & \\
\hline & 69 & \\
\hline & 73 & \\
\hline Rata-rata & 70 & \\
\hline \multirow{4}{*}{$35.000 \mathrm{~N}$} & 56 & \multirow{4}{*}{1.154701} \\
\hline & 54 & \\
\hline & 56,5 & \\
\hline & 54 & \\
\hline Rata-rata & 55 & \\
\hline
\end{tabular}

Berikut ini hasil plot grafik hubungan variasi tekanan dengan MRR, EWR dan kekerasan Rockwell.

Pengaruh Variasi Tekanan Kompaksi Powder Metallurgy Elektroda Metal Matrix Composites Tembaga-Grafit terhadap Material Removal Rate dan Electrode Relative Wear pada Proses EDM Mesin Chimer EZ

(Dwi Handoko, Sutrisno, Agus Rohermanto) 


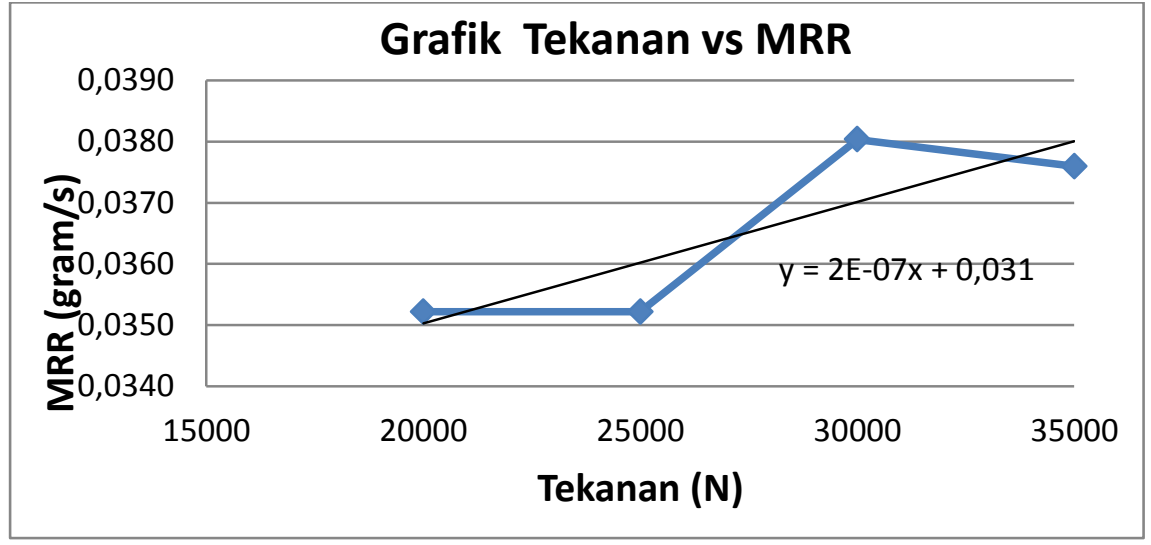

Gambar 1. Grafik hubungan Variasi Tekanan Elektroda terhadap MRR

Hasil pengujian pemesinan EDM pada masing-masing elektroda, pada grafik 1 menunjukkan semakin besar tekanan kompaksi yang dilakukan semakin besar kemampuan untuk menghasilkan Material Removal Rate (MRR) sedangkan tekanan yang tertinggi pada pengujian ini terjadi pada $30.000 \mathrm{~N}$ yaitu sebesar $0,03804 \mathrm{gram} / \mathrm{min}$. Hal ini terjadi dikarenakan terjadinya peningkatan kemampuan proses spark pada paduan tembaga dan grafit dikarenakan adanya sifat konduktifitas yang baik dari kedua material tersebut.

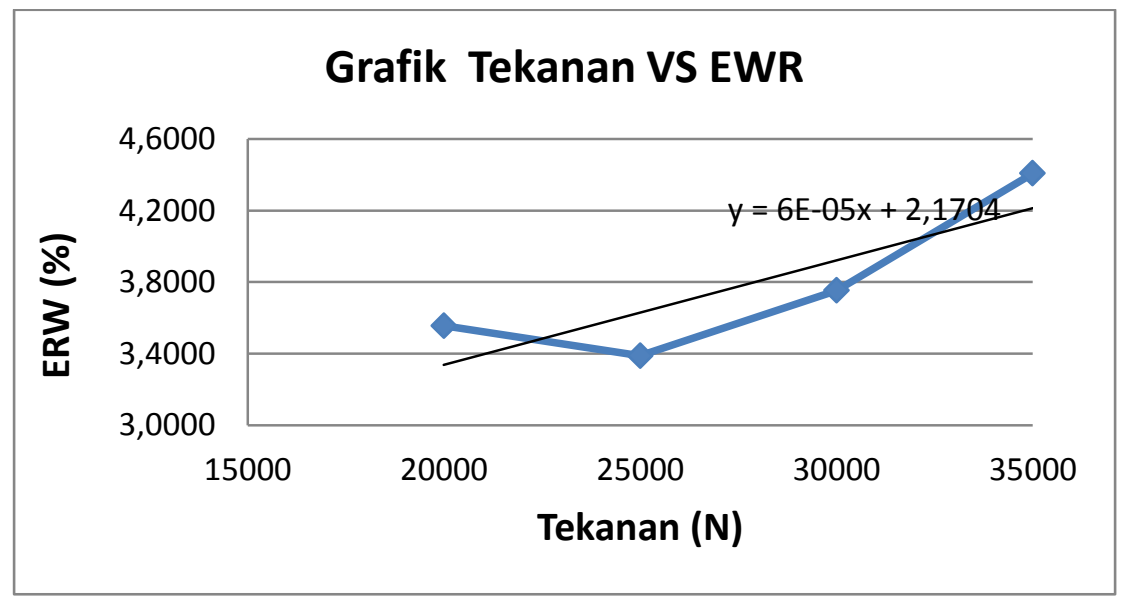

Gambar 2. Grafik hubungan Variasi Tekanan terhadap ERW

Grafik 2 menunjukkan bahwa semakin tinggi tekanan kompaksi yang diberikan, keausan elektroda juga relative mengingkat namun keausan ini sebagian besar dikarenakan terjadinya spark antar proses pembuangan benda kerja dan elektroda pada pengujian ini keausan elektroda minimum Electrode Relative Wear $(E R W)$ terjadi pada tekanan $25.000 \mathrm{~N}$. 


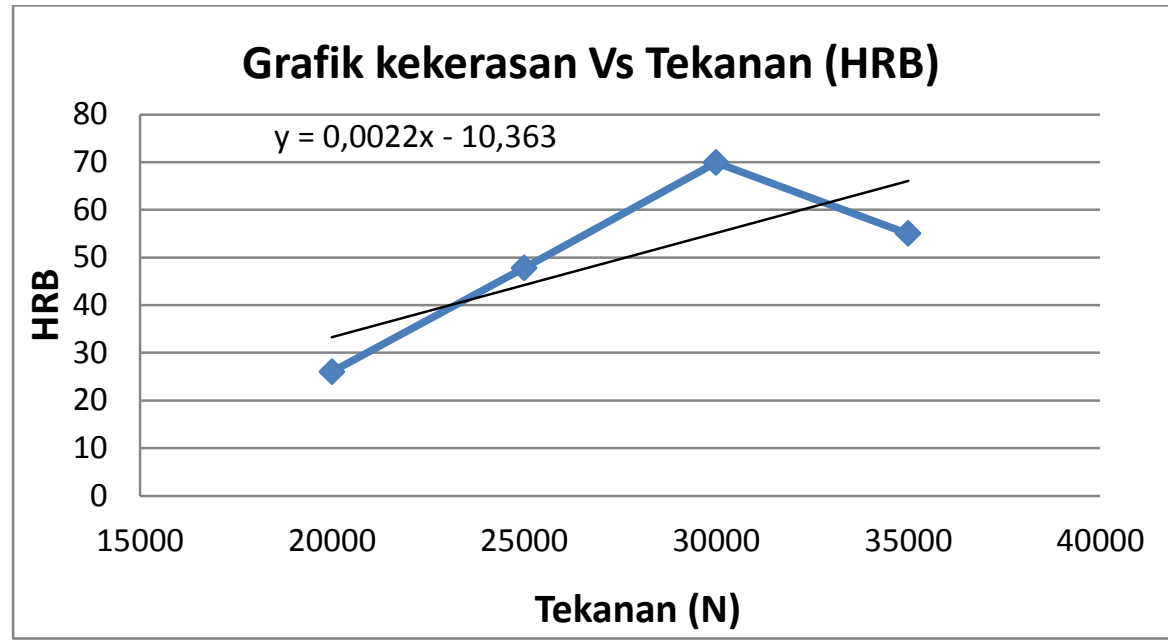

Gambar 3. Grafik hubungan Variasi Tekanan terhadap Kekerasan Elektroda

Grafik 3 menunjukkan bahwa semakin besar tekanan kompaksi dari pengujian telihat semakin meningkat kekerasan material elektroda, dimana kekerasan tetinggi tejadi pada tekanan $30.000 \mathrm{~N}$ yaitu sebesar $70 \mathrm{HRB}$, hal ini dimungkinkan dengan semakin padat dan rapatnya kontak material elektroda tembaga dan grafit.

Hasil pengujian mikrostruktur masing-masing elektroda dilakukan setelah melalui proses pemotongan, pengamplasan, polishing, etsa dengan menggunakan cairan kuprisulfat $\left(\mathrm{CuSO}_{4}\right)$ dan dihasilkan gambar sebagai berikut :

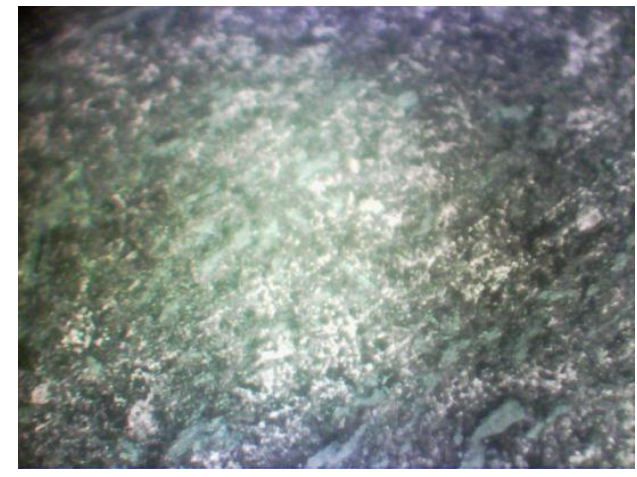

(a) Tekanan $20.000 \mathrm{~N}$

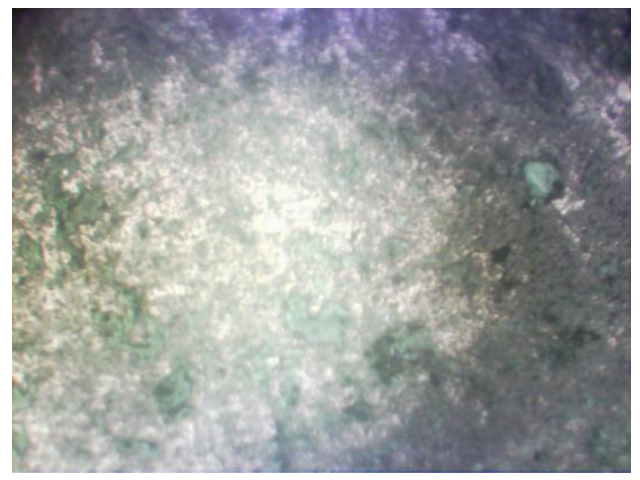

(b)Tekanan $25.000 \mathrm{~N}$

Pengaruh Variasi Tekanan Kompaksi Powder Metallurgy Elektroda Metal Matrix Composites Tembaga-Grafit terhadap Material Removal Rate dan Electrode Relative Wear pada Proses EDM Mesin Chimer EZ

(Dwi Handoko, Sutrisno, Agus Rohermanto) 


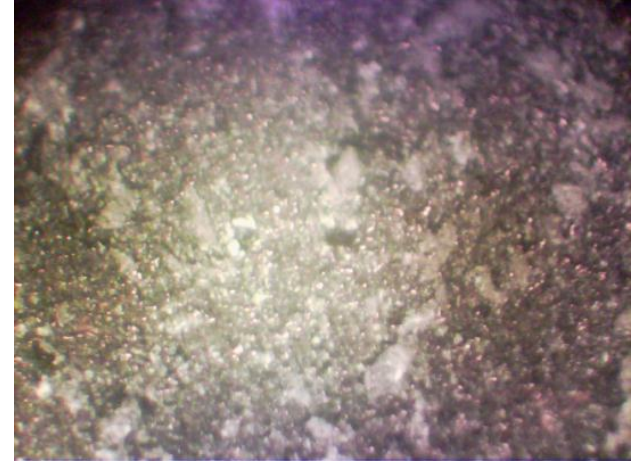

(c) Tekanan $30.000 \mathrm{~N}$

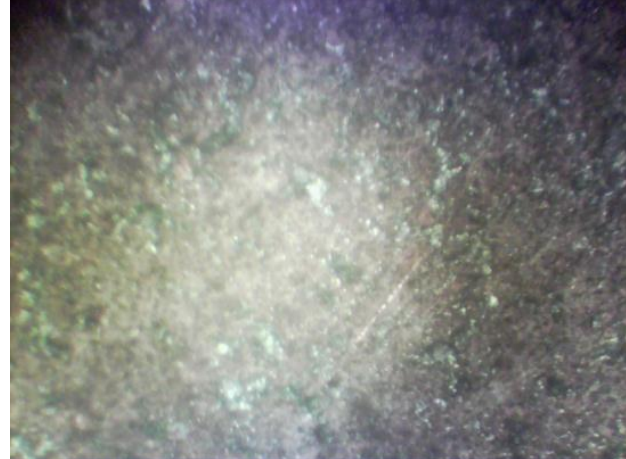

(d) Tekanan $35.000 \mathrm{~N}$

Gambar 5. Mikrostruktur elektroda dengan pembesaran $100 \mathrm{x}$

Dilihat dari struktur mikro dengan pembesaran $100 \mathrm{X}$ pada masing-masing elektroda, pada tekanan $20.000 \mathrm{KN}$ komposisi paduan antara grafit dan tembaga belum begitu menyatu atau terlihat butiran yang kasar, sedangkan semakin tinggi tekanan menunjukkan tembaga dan grafit tersebar merata dengan butiran yang padat dan lebih halus. Ini menunjukkan adanya rekristalisasi akibat terisinya ruang dan celah antara tembaga dan grafit yang semakin mengecil yang mengakibatkan elektroda menjadi keras.

\section{SIMPULAN}

Berdasarkan hasil penelitian yang telah kami lakukan, dapat disimpulkan bahwa pada penelitian ini dengan menggunakan empat jenis elektroda yang dibuat dari serbuk paduan tembaga dan grafit dengan variasi tekan kompaksi, secara keseluruhan bisa meningkatkan laju pemakan material (MRR). Pada variasi tekanan menunjukkan semakin meningkat tekanan kompaksi mengakibatkan laju keausan elektroda (EWR). Kekerasan elektroda semakin meningkat dengan meningkatnya tekanan kompaksi. Semakin tinggi tekanan menunjukkan tembaga dan grafit tersebar merata dengan butiran yang padat dan lebih halus. Ini menunjukkan adanya rekristalisasi akibat terisinya ruang dan celah antara tembaga dan grafit yang semakin mengecil yang mengakibatkan elektroda menjadi keras. 


\section{DAFTAR PUSTAKA}

[1] Petrus Londa. Pengaruh Variabel Pemotongan terhadap Keausan Elektroda dan Benda Kerja pada Proses EDM. Jurnal ROTASI - Vol. 16, No. 4, Oktober 2014: 9-16.

[2] Adi Muttaqin. Studi Eksperimental Pengaruh Variasi Jenis Material Elektroda terhadap Peformansi Pemesinan Drilling EDM Menggunakan EDM Tipe Relaksasi (Rc). Prosiding Seminar Nasional Manajemen Teknologi XX Program Studi MMT-ITS, Surabaya 1 Februari 2014.

[3] Fuller, E. John, Electric Discharge Machining, ASM International vol.16, pp. $557-564,2002$.

[4] Ahmad Junaidi, Pengaruh Temperatur Sinter terhadap Kekerasan Elektrode Tembaga-5\% Karbon yang Dibuat dengan Metode Serbuk Metalurgi. Jurnal Austenit Volume 3, Nomor 2, 2011.

[5] Patna Partana, Studi Pengaruh Material Elektroda pada Proses Electrical Discharge Machining, Jurnal Media Mesin, Surakarta, 2008.

[6] Suhardjono. Pengaruh Arc On dan Arc Off Time terhadap Kekasaran Permukaan dan Laju Pembuangan Geram Hasil Permesinan Sinking EDM. Jurnal Teknik Mesin, Vol.6 No. 1. 2004.

[7] Rival, Electrical Discharge Machining of Titanium Alloy Using Copper Tungsten Electrode With SiC Powder Suspension Dielectric Fluid, Thesis S2, Fakulti Kejuruteraan, Mekanikal, Universiti Teknologi Malayasia, 2005.

[8] Bagiasna, K. Proses-proses non Konvensional, Departemen Mesin, Institut Teknologi Bandung. 1978.

Pengaruh Variasi Tekanan Kompaksi Powder Metallurgy Elektroda Metal Matrix Composites Tembaga-Grafit terhadap Material Removal Rate dan Electrode Relative Wear pada Proses EDM Mesin Chimer EZ

(Dwi Handoko, Sutrisno, Agus Rohermanto) 